\title{
Experimental Study on Seeding Performance of Nest-eye Metering Device
}

\author{
Chen Fude $^{1,2, a}$, Meng Fanzhao 1, 2, b and Lv Jing ${ }^{1,2, c}$ \\ ${ }^{1}$ School of Mechanical Engineering, Shandong Huayu University of Technology, Dezhou 253034, China \\ ${ }^{2}$ Dezhou Municipal Key Laboratory of Industrial Robot Control, Dezhou 253034, China \\ a chenfude2008@126.com, ${ }^{\mathrm{b}}$ mfzhthy@163.com, ${ }^{\mathrm{c}}$ lvjing@163.com
}

Keywords: metering device, precision sowing machines, seeding performance, orthogonal experiments

\begin{abstract}
The seed metering device is the core working part of the precision seed drill, and its seeding performance directly determines the precision sowing machines. The seed-discharging mechanism and seeding performance of the adjustable nest-type seed metering device are studied, and optimal working parameters are determined. Finally, the gantry performance experiment is conducted. Through the single-factor tests and the orthogonal tests, it showed that the rotation speed of seed tray is the main factor affecting the seeding performance, and the optimal parameters are obtained.
\end{abstract}

\section{Introduction}

In recent years, with the continuous development of seed processing technology and precision sowing technology, the widespread application of precision sowing machines has become the main characteristics and development direction of modern sowing technology [1]. Precision sowing machines abroad is widely used in on-demand corn, soybean, cotton, sorghum, sugar beet and other cultivated crops, whose advantages includes saving seed, without seedlings, fine distribution of field plants evenly distributed to achieve close planting density, being conducive to seedling growth, and increasing production [2]. Metering device is one of the core components of sowing machines. Seeding performance is directly related to the quality of planting [3]. In order to master the seeding performance of the adjustable eye-drop sowing machine, it carried out the performance test and conducted the single factor test and the orthogonal test, and at the same time, the factors that affect the seeding performance are analyzed. The determinant factors of the primary and secondary parameters and optimal parameters provide the design reference for the agricultural production, and achieve the improvement of structure and performance optimization of the sowing machine.

\section{Working principle of metering device}

The seeds in the filling room are filled by gravity into the rotating eye socket of the rotating eye socket; when the nest-eye wheel passes through the brush wheel of the clear rotating type which is rotated in the reverse direction, the excess seed is excluded. It leaves only a seed, and continues to rotate with the nest wheel into the care area, to the place of seed placement below the unloading, the seeds by their gravity or scraper to leave the hole, through the guide tube into the ditch within, so as to achieve a single precision sowing.

\section{Experiment materials and methods}

\subsection{Experiment materials and methods}

The equipment materials used in the experiment are internal single No. 4 corn seeds, the triaxial dimensions are $10.2 \mathrm{~mm}$ long, $9.8 \mathrm{~mm}$ wide, and $5.6 \mathrm{~mm}$ thick, the moisture content is $14.0 \%$, and the weight of a thousand grains is $380 \mathrm{~g}$. The seed metering device used in the experiment is an adjustable nest-eyes. This equipment is conducted on the JPS-12 seed metering performance test 
bench. This test bench is based on computer vision technology and can realize real-time detection of seeding performance. It is suitable for all kinds of metering devices, test and verification of sowing, hole casting and drilling performance. Seed metering equipment bed is to use the conveyor belt as a seedbed, and simulate field work sowing machine movement speed, the seed metering device stationary in the test, the conveyor belt (seedbed) relative to the seeder movement. During the equipment, it takes the middle section of the seed plate and seed bed with smooth running as a statistical sample, and measures 250 grain intervals for each working condition and repeats for 3 times, taking the average value. The statistical and evaluation criteria for the equipment results are based on the GB/T 6973-2005 single grain (precision) planter equipment method[4].

\subsection{Single factor test}

This paper focuses on two factors that have a significant impact on it, the rotational speed of the seed tray and nest length. Considering the actual work requirements and agronomic requirements, the seed bed speeds in the following tests are all chosen to be $5.4 \mathrm{~km} / \mathrm{h}$.

\subsubsection{Effect of Seed Disc Rotation Speed on Seeding Performance}

Single-factor test is carried out at speeds of $20 \mathrm{r} / \mathrm{min}, 35 \mathrm{r} / \mathrm{min}, 50 \mathrm{r} / \mathrm{min}, 65 \mathrm{r} / \mathrm{min}, 80 \mathrm{r} / \mathrm{min}$ and nest length of $9 \mathrm{~mm}$. The effect of the change of seed plate speed on seed metering performance is studied respectively. Equipment data fitting curves are shown in Figure 1.

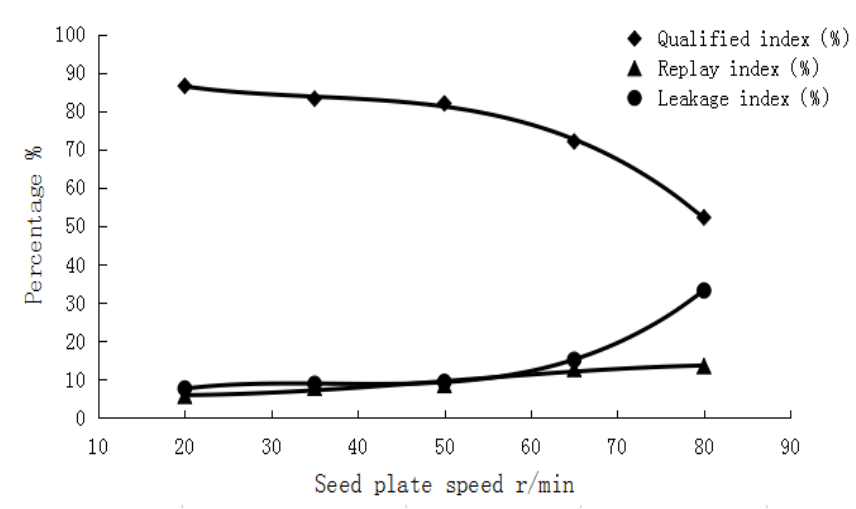

Figure 1 Seeding performance influence on seed plate speed

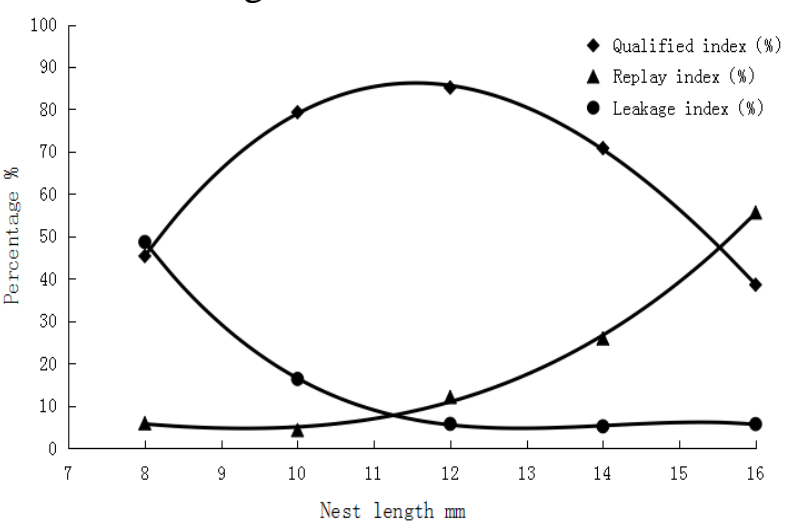

Figure 2 Seeding performance influence on the length of the nest-eyes

The speed of the seed plate is between 20-60 r/min, the seeding performance index is better. When the seed metering tray is too slow, the seeds have sufficient time to fill the nest, and the seed brush removes the excess seed to ensure a high single grain compliance index, but the working efficiency is too low, affecting the normal production. When seed plate speed is too fast, the seeds cannot successfully enter the nest-eyes, resulting in serious leakage.

\subsubsection{Influence of Nest Length on Seeding Performance}

In the seedbed with a speed of $5.4 \mathrm{~km} / \mathrm{h}$, seed wheel rotation speed $40 \mathrm{r} / \mathrm{min}$, nest length of $8 \mathrm{~mm}$, $10 \mathrm{~mm}, 12 \mathrm{~mm}, 14 \mathrm{~mm}, 16 \mathrm{~mm}$ five levels of single factor test is selected. Equipment data fitting curves are shown in Figure 2. As the eye length is between 9 and $12 \mathrm{~mm}$, the performance index of seeding was good. When the nest is too small, the seeds cannot be smoothly filled into the nest, resulting in more serious leakage. When the nest is too large, the chance of the seed filling into the nest increases, and two seeds may enter the nest simultaneously. At this point, it is impossible for the seed brushes to remove them, thereby increasing the replay number of the seeds and reducing the number of single grain passes.

\subsection{Orthogonal experiment design}

According to the single factor experiment and experimental data analysis, the experimental indexes are better when the speed of seed plate is $20 \sim 60 \mathrm{r} / \mathrm{min}$ and the length of nest eye is $9 \sim 12 \mathrm{~mm}$. It selected plate speed and nest eye length design of two factors and three levels of orthogonal test, 
orthogonal test factors and levels are shown in Table 1.

Table 1 Factors and the levels of the orthogonal experiment

\begin{tabular}{c|cc}
\hline factor & $\begin{array}{c}\text { Seed plate speed }(\mathrm{r} / \mathrm{min}) \\
\mathrm{A}\end{array}$ & \\
\hline 1 & & \\
2 & 40 & 10 \\
3 & 50 & 11 \\
\hline
\end{tabular}

\section{Result analysis}

In the experiments, speed of the seed plate and nest length are the main factors affecting the test index. Therefore, the orthogonal experiments with two factors and three levels are designed. Considering the interaction between speed of the seed plate and nest length, the $\boldsymbol{L}_{9}(34)$ orthogonal experiment table is used. Experimental result and range analysis are shown in Table 2.

Table 2 Orthogonal experiment program results and range analysis

\begin{tabular}{|c|c|c|c|c|c|c|c|}
\hline Test number & $\begin{array}{c}\text { Seed plate } \\
\text { speed } \\
\mathrm{A}(\mathrm{r} / \mathrm{min}) \\
\end{array}$ & $\begin{array}{c}\text { Nest length } \\
\mathrm{B}(\mathrm{mm}) \\
\end{array}$ & $\begin{array}{c}\mathrm{A} 、 \mathrm{~B} \\
\text { Interaction } \\
\mathrm{A} \times \mathrm{B} \\
\end{array}$ & $\begin{array}{c}\text { Empty column } \\
\text { D } \\
\end{array}$ & $\begin{array}{c}\text { Qualified } \\
\text { index } \\
\mathrm{A}_{\mathrm{j}}(\%) \\
\end{array}$ & $\begin{array}{c}\text { Replay index } \\
\text { D (\%) }\end{array}$ & $\begin{array}{c}\text { Leakage index } \\
\text { M (\%) }\end{array}$ \\
\hline 1 & 1 & 1 & 1 & 1 & 86.15 & 4.17 & 9.68 \\
\hline 2 & 1 & 2 & 2 & 2 & 80.30 & 11.83 & 7.87 \\
\hline 3 & 1 & 3 & 3 & 3 & 77.31 & 12.31 & 10.38 \\
\hline 4 & 2 & 1 & 2 & 3 & 87.78 & 3.33 & 8.89 \\
\hline 5 & 2 & 2 & 3 & 1 & 78.57 & 10.24 & 11.19 \\
\hline 6 & 2 & 3 & 1 & 2 & 88.00 & 8.00 & 4.00 \\
\hline 7 & 3 & 1 & 3 & 2 & 75.74 & 9.81 & 14.54 \\
\hline 8 & 3 & 2 & 1 & 3 & 73.64 & 11.36 & 15.00 \\
\hline 9 & 3 & 3 & 2 & 1 & 80.09 & 8.08 & 11.82 \\
\hline$A_{j 1}$ & 81.253 & 83.223 & 82.597 & 81.603 & & & \\
\hline$A_{j 2}$ & 84.783 & 77.503 & 82.723 & 81.347 & & & \\
\hline$A_{j 3}$ & 76.490 & 81.800 & 77.207 & 79.577 & & $\mathrm{~T}=727.58$ & \\
\hline Extremely poor $\mathrm{R}_{\mathrm{A}}$ & 8.293 & 5.7200 & 5.516 & 2.026 & & & \\
\hline $\begin{array}{l}\text { Primary and secondary } \\
\text { factors }\end{array}$ & & & $A \times B$ & & & & \\
\hline Optimal combination & & & & & & & \\
\hline $\mathrm{D}_{1}$ & 9.437 & 5.770 & 7.843 & 7.497 & & & \\
\hline $\mathrm{D}_{2}$ & 7.190 & 11.143 & 7.747 & 9.880 & & & \\
\hline $\mathrm{D}_{3}$ & 9.750 & 9.463 & 10.787 & 9.000 & & $\mathrm{~T}=79.13$ & \\
\hline Extremely poor $R_{D}$ & 2.560 & 5.373 & 3.040 & 2.383 & & & \\
\hline $\begin{array}{l}\text { Primary and secondary } \\
\text { factors }\end{array}$ & & & $\mathrm{B}>\mathrm{A}$ & & & & \\
\hline Optimal combination & & & & & & & \\
\hline $\mathrm{M}_{1}$ & 9.310 & 11.003 & 9.560 & 10.897 & & & \\
\hline $\mathrm{M}_{2}$ & 8.027 & 11.353 & 9.527 & 8.770 & & & \\
\hline $\mathrm{M}_{3}$ & 13.753 & 8.733 & 12.003 & 11.423 & & $\mathrm{~T}=93.27$ & \\
\hline Extremely poor $R_{M}$ & 5.726 & 2.620 & 2.467 & 2.653 & & & \\
\hline $\begin{array}{l}\text { Primary and secondary } \\
\text { factors }\end{array}$ & & & $A \times B$ & & & & \\
\hline Optimal combination & & & & & & & \\
\hline
\end{tabular}

Table 3 Variance analysis

\begin{tabular}{|c|c|c|c|c|c|c|}
\hline index & Sources of variance & $\begin{array}{c}\text { Deviation square } \\
\text { sum }\end{array}$ & $\begin{array}{c}\begin{array}{c}\text { Degree of } \\
\text { freedom }\end{array} \\
\end{array}$ & $\begin{array}{c}\text { Mean square } \\
\text { value }\end{array}$ & F ratio & Significance \\
\hline \multirow[t]{4}{*}{ Qualified index } & $\bar{A}$ & 103.930 & 2 & 51.965 & 14.2 & ** \\
\hline & B & 53.206 & 2 & 26.603 & 7.30 & $*$ \\
\hline & $A \times B$ & 59.502 & 2 & 29.751 & 8.10 & $*$ \\
\hline & Error e & 7.306 & 2 & 3.653 & & \\
\hline \multirow[t]{4}{*}{ Replay index } & A & 11.699 & 2 & 5.850 & 1.34 & not significant \\
\hline & B & 45.336 & 2 & 22.67 & 5.20 & $*$ \\
\hline & $A \times B$ & 17.914 & 2 & 8.957 & 2.05 & not significant \\
\hline & Error e & 8.715 & 2 & 4.360 & & \\
\hline \multirow[t]{4}{*}{ Leakage index } & A & 54.185 & 2 & 27.09 & 4.58 & $*$ \\
\hline & B & 12.140 & 2 & 6.07 & 1.03 & not significant \\
\hline & $A \times B$ & 12.105 & 2 & 6.05 & 1.02 & not significant \\
\hline & Error e & 11.840 & 2 & 5.92 & & \\
\hline
\end{tabular}

Note: * representative of significant and more significant; ** representative is very significant

The goal of the experiment is that the higher the single qualified index, the lower the leakage index and replay index, the better seeding performance. Taking the agronomic requirements into 
account, the sowing single grain pass index should be more than $85 \%$, leakage sowing index should be kept within $5 \%{ }^{[5]}$. According to the above analysis and after comprehensive balance, the final combination of the best factor for this test is $A_{2} B_{3}$. Variance analysis is shown in Table 3. The variance of the results of the variance analysis of the test results is consistent with the intuitive analysis results, indicating that the range analysis is accurate. Through intuitive analysis and analysis of variance, the best combination of factor levels is $A_{2} B_{3}$.

\section{Conclusions}

1) When the rotation speed of the seed plate is $20-60 \mathrm{r} / \mathrm{min}$ and the length of the cavity is 9-12mm, and the seeding performance index is better.

2) Through the orthogonal experiment range and variance analysis, the rotation speed of seed row is the main factor affecting the seed quality of the adjustable nest seed metering device. The optimal combination of the best seedling conditions for seed metering is, the disk speed is $50 \mathrm{r} / \mathrm{min}$ and the length of the socket is $11 \mathrm{~mm}$, at this time, the corn single-pass qualified index reaches $88 \%$, and the leakage sowing index attains $4 \%$.

\section{References}

[1] Zhang Boping.(1997) Modern Planting Machinery Engineering [M]. Beijing: Machinery Industry Press.

[2] Chen Lidong, He Di. (2006) Research on the Current Situation and Development Trend of Precision Seeding Device [J]. Agricultural Mechanization Research, 4,16-18.

[3] Liu Hongxin, Wang Fulin. (2007) Factor Selection and Analysis on the Experimental Study of Seed-metering Device [J]. Agricultural Mechanization Research, 5,77-79

[4] National Bureau of Standards. GB6973-86 single grain (precision) seeder test method [S] Beijing: China Standard Press, 2005.

[5] Ren Luquan. Experimental Design and Analysis (2 edition) [M]. Beijing: Higher Education Press, 2003. 